\title{
Clinicopathologic features of primary colonic enteropathy-associated T cell lymphoma type II in an elderly Asian male with diarrhea
}

\author{
Jey-Hsin Chen • Diane Bai • Vik Dabhi • Brent L. Wood • \\ Steven J. Kussick
}

Received: 24 November 2014 / Accepted: 22 January 2015 /Published online: 4 February 2015

(C) Springer-Verlag Berlin Heidelberg 2015

\begin{abstract}
A 76-year-old Asian man with a 6-month history of intractable watery diarrhea proceeded to colonoscopic examination that revealed diffusely dull-appearing colonic mucosa with focal areas of superficial ulceration. Mucosal biopsies demonstrated a neoplastic population of monomorphous small-to-intermediate-sized CD8+/CD56+ cytotoxic T cells that densely infiltrated the surface epithelium and crypts in a near pan-colonic distribution without tumor formation. Clinical staging revealed no disease elsewhere. The patient was treated aggressively with chemotherapy but died from disease five and a half months after presentation. In all likelihood, the
\end{abstract}

J.-H. Chen $(\bowtie)$

CellNetix Pathology and Laboratories, 1124 Columbia Street,

Suite 200, Seattle, WA 98104, USA

e-mail: jchen@cellnetix.com

J.-H. Chen

Swedish Medical Center, Seattle, WA, USA

D. Bai

Division of Gastroenterology, Pacific Medical Center,

Seattle, WA, USA

V. Dabhi

Division of Hematology and Oncology, Pacific Medical Center, Seattle, WA, USA

B. L. Wood

Department of Laboratory Medicine, University of Washington Medical Center, Seattle, WA, USA

B. L. Wood

Seattle Cancer Care Alliance, Seattle, WA, USA

S. J. Kussick

PhenoPath Laboratories, Seattle, WA, USA patient had primary colonic involvement by enteropathyassociated T cell lymphoma (EATL) type II, a rare and aggressive extranodal non-Hodgkin lymphoma that occurs more commonly in Asians in whom celiac disease is infrequent. Widespread colonic disease in the absence of a massforming infiltrate has not been characterized in EATL type II and highlights an expanded clinical and pathological spectrum of the disease.

Keywords Enteropathy-associated Tcell lymphoma(EATL) · Primary intestinal T cell lymphoma (ITL) · Monomorphic ·

Cytotoxic T cells $\cdot$ Natural killer (NK) cells

\section{Abbreviations \\ EATL Enteropathy-associated T cell lymphoma \\ ITL Primary intestinal T-cell lymphoma \\ NK Natural killer}

\section{Introduction}

Primary intestinal T cell lymphoma (ITL) is a rare group of extranodal non-Hodgkin lymphoma of which enteropathyassociated T cell lymphoma (EATL) is the most common. Two types of EATL are currently recognized by the World Health Organization. Type I disease occurs primarily in Caucasians, is frequently associated with celiac disease and malabsorption, and is characterized by polymorphous intermediate-to-large-sized neoplastic cells. Type II disease, by contrast, is more common among Asians, is characterized by monomorphous small-to-intermediate-sized cells positive 
for cytotoxic T/natural killer (NK) cell markers, and is only infrequently associated with celiac disease or malabsorption. Herein, we describe a 76-year-old Asian man who presented with diarrhea due to a primary colonic $\mathrm{T}$ cell lymphoma with clinicopathologic similarities to EATL type II. The neoplasm involved the colonic mucosa in a near pan-colonic distribution with striking epitheliotropism but was without an intestinal mass-forming infiltrate which in all probability is consistent with primary colonic manifestation of EATL type II.

\section{Clinical history}

A 76-year-old Asian man presented to our facility with a 6month history of persistent watery diarrhea that was initially diagnosed and successfully treated for Clostridium difficile, confirmed by serial negative toxin assays. A physical examination revealed an elderly slender man with a non-tender, nondistended abdomen, and no palpable lymph nodes or hepatosplenomegaly. His medical history was notable for psoriasis and inflammatory arthritis, but he had no antecedent history of celiac disease, malabsorption, or inflammatory bowel disease. The patient proceeded to colonoscopy, which was remarkable for colonic mucosa that appeared focally inflamed with patchy areas of shallow ulceration (Fig. 1). The remainder of the colonic mucosa was vaguely dull in appearance. There was no endoscopic appearance of a polyp or a mass. Biopsies of the colon from the cecum to the rectum were obtained.

\section{Materials and methods}

The biopsy samples were fixed in $10 \%$ neutral buffered formalin and processed and stained with routine hematoxylin and eosin. Immunostains for CD3 (Ventana Medical System, 2GV6, $0.4 \mu \mathrm{g} / \mathrm{mL}$ ), CD20 (Ventana Medical System, L26, $0.3 \mu \mathrm{g} / \mathrm{mL}$ ), CD56 (Dako, 123C3, 1:100), CD4 (Leica

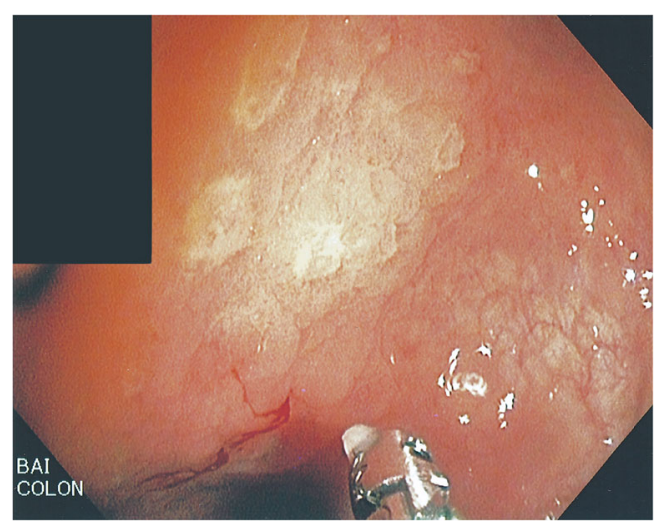

Fig. 1 Endoscopically dull-appearing colonic mucosa with foci of shallow ulceration
Biosystems, 4B12, 1:250), CD8 (Dako, C8/144B, 1:100), CD2 (Leica Biosystems, AB75, 1:50), CD5 (Leica Biosystems, 4C7, 1:100), CD7 (Biocare Medical, 272, 1:25), CD57 (PhenoPath, HNK-1, 1:5), CD30 (Ventana Medical System, Ber-H2, $1 \mu \mathrm{g} / \mathrm{mL}$ ), CD103 (Epitomics, EPR4166(2), 1:1000), TIA-1 (Immunotech Laboratories, 2G9A10F5, 1:1000), and TCR- $\beta$ F1 (Thermo Fisher Scientific, $8 \mathrm{~A} 3,1: 25)$ following antigen retrieval were visualized using polymer-based immunoperoxidase reaction and counterstained with hematoxylin. In situ hybridization for EpsteinBarr virus-encoded small RNA using fluorescein-conjugated oligonucleotide probes (Leica Biosystems, EBER, $0.1 \mu \mathrm{g} /$ $\mathrm{mL}$ ) was performed in conjunction with positive and negative reagent controls. T cell receptor gamma (TCR $\gamma$ ) gene rearrangement studies were performed on purified genomic DNA (Qiagen, Puregene), amplified by multiplex PCR using fluorescently labeled primers for the $\mathrm{V} \gamma \mathrm{I}$ and $\mathrm{V} \gamma \mathrm{II}$ variable regions and for the $J \gamma 1 / 2$ and $J \gamma \mathrm{P} 1 / 2$ joining regions of $\mathrm{TCR} \gamma$, and size fractionated on an ABI 3130 Sequence Analyzer (Applied Biosystems).

\section{Results}

Histopathologic examination showed a neoplastic population of lymphocytes that involved the mucosa throughout the length of the colon with relative sparing of the descending and sigmoid colon. The neoplastic cells were monomorphic, small-to-intermediate in size with round-to-irregular nuclei, condensed chromatin, indistinct-to-small nucleoli, and smallto-moderate amounts of pale or clear cytoplasm (Fig. 2). The cells infiltrated the colonic mucosa with marked epitheliotropism, densely infiltrating and obscuring the surface and crypt epithelia with extension to their apical surfaces. The lymphocytes infiltrated the epithelium singly but in a few foci aggregated to form small intraepithelial Pautrier-like microabscesses. There was no necrosis or large cell transformation of the neoplastic population. Rare mitotic figures were observed. The lamina propria was variably expanded, greater in the right than the left colon, by a small number of the neoplastic cells intermixed with reactive lymphocytes, plasma cells, eosinophils, and occasional neutrophils. The accompanying epithelial injury was characterized by apoptosis, desquamation of cells into the crypt lumen, regeneration of damaged crypts, atrophy, and focal ulceration. Also present were features of chronic mucosal injury, including mild crypt shortening, focal loss of crypts, and Paneth cell metaplasia in the left colon, but the characteristic changes associated with chronic inflammatory bowel disease such as established basal plasmacytosis and branching crypts were absent.

Immunoperoxidase studies showed that the neoplastic lymphocytes were $\mathrm{T}$ cells positive for $\mathrm{CD} 3, \mathrm{CD} 2, \mathrm{CD} 7, \mathrm{CD} 8$, CD56, CD103, TIA-1, and TCR- $\beta$ F 1 and negative for 
Fig. 2 Histopathologic features of primary colonic epitheliotropic CD8+/CD56+ T cell lymphoma. The neoplasm is characterized by monomorphic small-tointermediate-sized cells that diffusely infiltrate colonic mucosa with striking epitheliotropism (a, $\times 10)$, obscuring the surface $(\mathbf{b}$, $\times 40)$, and crypt $(\mathbf{c}, \times 20)$ epithelia with formation of occasional small intraepithelial Pautrier-like microabscesses $(\mathbf{d}, \times 60)$. The accompanying epithelial injury is characterized by scattered apoptotic bodies $(\mathbf{e}, \times 60)$ and focal mucosal ulceration $(\mathbf{f}, \times 20)$
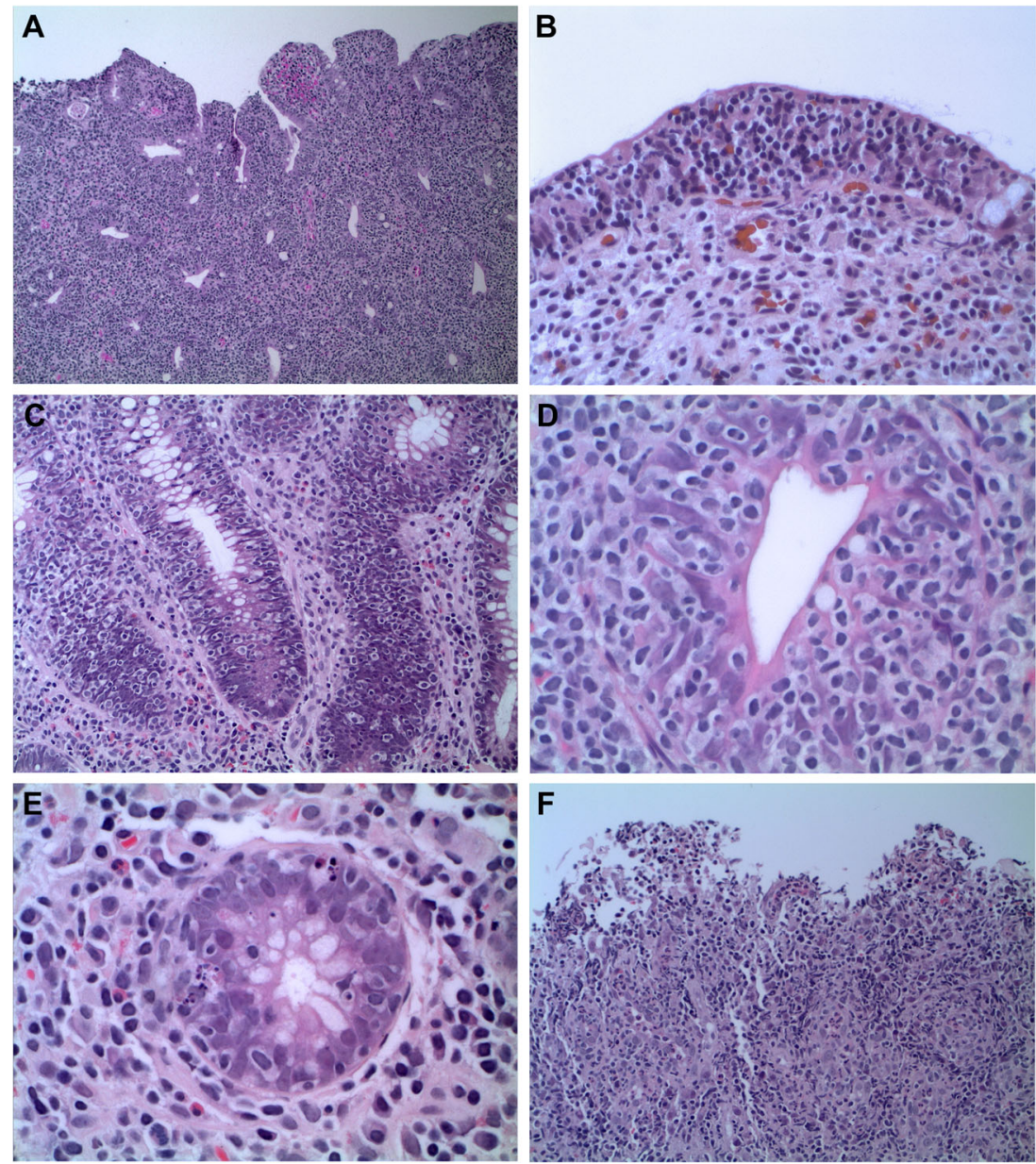

CD20, CD4, CD5, CD57, and CD30 (Fig. 3). Intermixed reactive $\mathrm{CD} 4$-positive $\mathrm{T}$ cells were located predominantly in the lamina propria. B cells, highlighted by CD20, were limited to rare basal lymphoid aggregates. An immunostain for CMV was negative, as was in situ hybridization for Epstein Barr virus-encoded small nuclear RNA (EBER). Polymerase chain reaction performed on paraffin-embedded tissue detected clonal gene rearrangement of the T cell receptor (TCR) $\gamma$ chain in the neoplastic $\mathrm{T}$ cell population.

Disease staging with a positron emission tomography/ computed tomography (PET/CT) scan revealed increased SUV activity in the colon and rectum, but no appreciable activity elsewhere. There was no lymphadenopathy or organomegaly. His serum LDH was within normal limits. A staging bone marrow biopsy was deferred. The patient was treated with an attenuated chemotherapy regimen of cyclophosphamide, adriamycin, vincristine, and prednisone (CHOP) at 3-week intervals, resulting in symptomatic improvement including a decrease in diarrhea. Unfortunately, within 4 months following 5 cycles of CHOP therapy, the patient developed progressive fatigue, anorexia, recurrent diarrhea, and a marked decline in his performance status. A repeat colonoscopic evaluation revealed recurrent/persistent disease. The patient was transitioned to hospice care and expired five and half months following his diagnosis. An autopsy was not requested.

\section{Discussion}

Primary intestinal T cell lymphoma (ITL) is a rare, heterogeneous group of extranodal non-Hodgkin lymphoma of which the most common and best characterized is enteropathyassociated T cell lymphoma (EATL) [1,2]. EATL is clinically aggressive, associated with $70 \%$ mortality within 6 months of diagnosis, and typically presents as a mass-forming infiltrate in the small intestine with histological features of enteropathy in the surrounding non-tumorous mucosa. The tumor is often multifocal, involves the intestine transmurally, and exhibits a high tendency toward ulceration, bowel obstruction, and/or perforation. Based on clinical, serological, histopathologic, and genetic features, two types of enteropathy-associated $\mathrm{T}$ cell lymphoma are currently recognized by the World Health Organization [3-5]. Type I, or the classical form of EATL, is frequently associated with celiac disease and malabsorption and occurs primarily in the Caucasian population of northern 
Fig. 3 Immunophenotypic features of primary colonic epitheliotropic CD8+/CD56+ T cell lymphoma $(\times 20)$. a CD3, b CD8, c CD56, d TIA-1, e CD103, f TCR- $\beta \mathrm{F} 1$
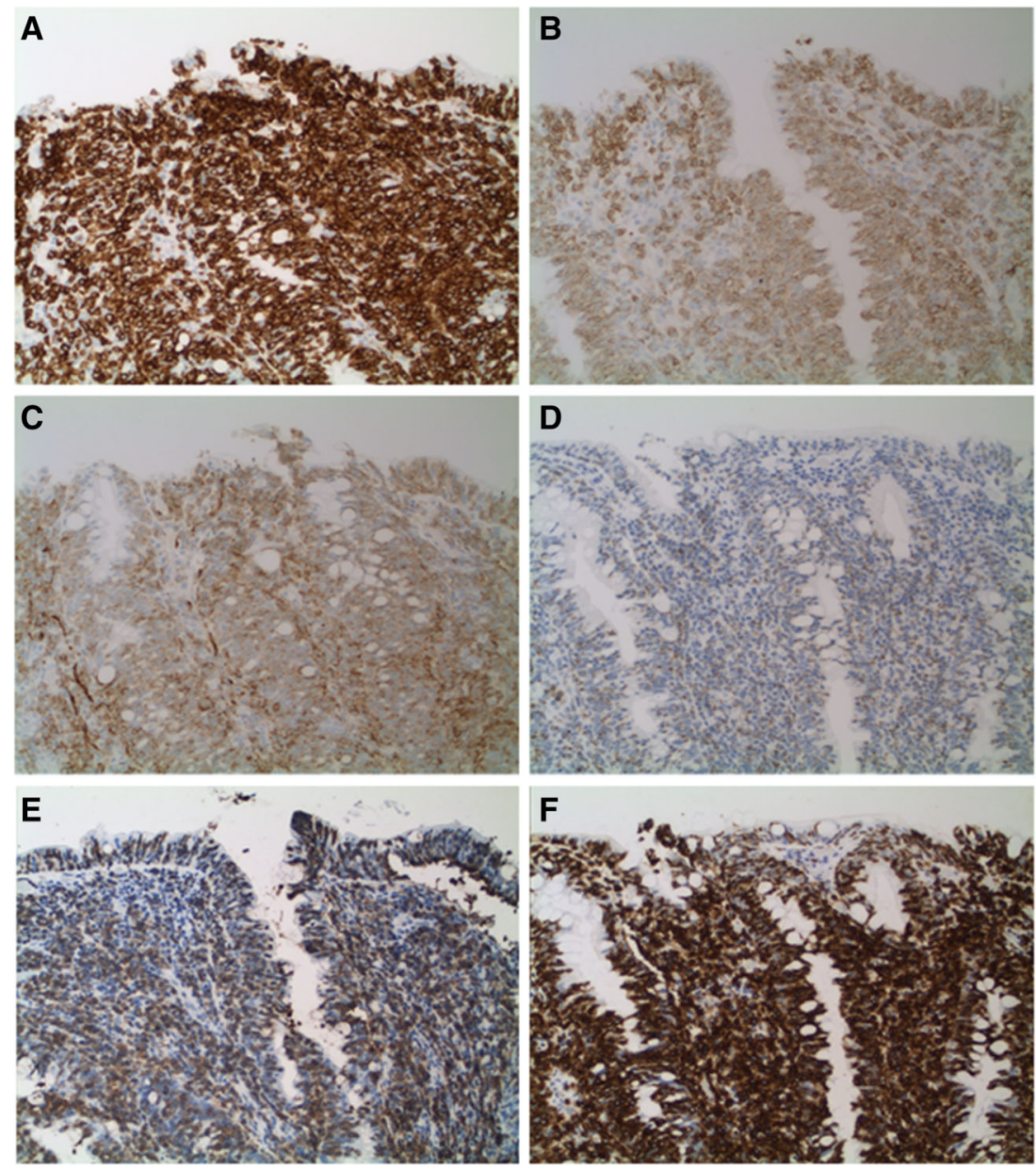

European descent. It is typically limited to the small intestine, often associated with histological features of enteropathy in the adjacent mucosa, and characterized by polymorphous medium-to-large sized neoplastic cells with immunoblastic and/or high-grade features and an immunophenotypic profile that is negative for CD4, CD8, and CD56. Type II, by contrast, is less commonly associated with an enteropathy or malabsorption and has a broader geographic and ethnic distribution. It mainly involves the small intestine but can also involve the colon and is characterized by monomorphous small-tomedium-sized lymphocytes that co-express CD8 and CD56 in the majority of cases and lack high-grade histologic features or angioinvasive properties [4-10].

Since the refinement in the classification of EATL, there has been growing interest in ITL and EATL in the Asian population in whom the frequency of celiac disease is low and Epstein-Barr virus (EBV) infection and extranodal T/NK cell lymphoma are more prevalent [6-17]. In European patients, EATL comprises the majority of ITL and is composed of approximately $80-90 \%$ type I and 10-20\% type II disease, reflecting the high prevalence of celiac disease in this population. In Asians of the Far East, in whom celiac disease has only been rarely reported, EATL comprises a smaller proportion of ITL and is composed predominantly, if not exclusively, of type II disease. Although the clinicopathologic and genetic features of EATL type II in Asian and Western patients are similar in many respects, including an absence of an etiologic association with celiac disease in most cases, there appears to be more variable clinical and/or histopathological association with an enteropathy or malabsorption, greater prevalence of colonic involvement, and a higher frequency of neoplastic T cells expressing TCR- $\gamma \delta$ in the Asian population $[4-7,10,12-15,18]$.

This patient's ITL shares many clinicopathologic similarities with EATL type II. It was a clinically aggressive neoplasm that presented insidiously as diarrhea in an elderly Asian man who had no prior history of celiac disease or malabsorption. The neoplastic T cells were monomorphous, small-tointermediate in size, demonstrated prominent epitheliotropism, and expressed CD103, the human mucosal lymphocyte- 1 antigen that is commonly expressed in intraepithelial $\mathrm{T}$ lymphocytes and cytotoxic T/NK cellassociated markers CD8, CD56, and TIA-1 with loss of the pan-T cell marker CD5 and absent CD30 expression. Nevertheless, the patient's near pan-colonic disease involvement and absence of an intestinal mass-forming infiltrate are 
dissimilar to the characteristic mass-forming and zonal features of EATL type II. Although EATL is defined as a neoplasm of intraepithelial T cells, the clinicopathologic studies of EATL type II have largely been focused on clinical or surgically resected small intestinal masses [5, 7-10,13, 15, 16, 19]. While type II disease limited to the colon is uncommon, comprising at most $18 \%$ in one study [10], the clinicopathologic colonic manifestations have not been well characterized and there has been no reported case to date of type II disease without a clinically apparent intestinal mass. Secondly, epitheliotropic neoplastic cells are typically limited to the small intestinal mucosa immediately adjacent to a central tumor-forming zone $[7,13$, 16]. Although reports of discontinuous or distant intraepithelial involvement away from a mass are emerging $[7,13,20]$, this disease pattern appears to be an infrequent finding.

In all likelihood, this patient had primary colonic involvement by EATL type II due to the similarities in their aggressive clinical course, monomorphic small-to-intermediate cell size, expression of cytotoxic T/NK cell immunophenotypic profile, and epitheliotropism. The clinical and endoscopic features of our patient's disease are reminiscent of primary colonic $\mathrm{T}$ cell lymphoma in Korean patients in whom there was a high association with diarrhea, diffuse colonic disease involvement, endoscopic impression of an ulcerative/infiltrative process, and low association with a mass-forming infiltrate [21]. In the absence of an intestinal mass, the patient's neoplasm may represent an "early" (i.e., epitheliotropic) manifestation of EATL type II; however, the patient's rapid clinical decline suggests that intraepithelial-predominant disease may be as clinically aggressive as those associated with an intestinal mass-forming neoplasm.

Conflict of interest The authors declare that they have no conflict of interest.

\section{References}

1. Swerdlow SH, Jaffe ES, Brousset P, Chan JK, de Leval L, Gaulard P et al (2014) Cytotoxic T-cell and NK-cell lymphomas: current questions and controversies. Am J Surg Pathol 38:e60-e71

2. O'Malley DP, Goldstein NS, Banks PM (2014) The recognition and classification of lymphoproliferative disorders of the gut. Hum Pathol 45:899-916

3. Bosman FT, Carneiro F, Hruban RH, Theise ND (eds) (2010) WHO classification of tumours of the digestive system. International Agency for Research on Cancer, Lyon

4. Deleeuw RJ, Zettl A, Klinker E, Haralambieva E, Trottier M, Chari R et al (2007) Whole-genome analysis and HLA genotyping of enteropathy-type T-cell lymphoma reveals 2 distinct lymphoma subtypes. Gastroenterology 132:1902-1911

5. Chott A, Haedicke W, Mosberger I, Fodinger M, Winkler K, Mannhalter C et al (1998) Most CD56+ intestinal lymphomas are CD8+CD5-T-cell lymphomas of monomorphic small to medium size histology. Am J Pathol 153:1483-1490
6. Ko YH, Karnan S, Kim KM, Park CK, Kang ES, Kim YH et al (2010) Enteropathy-associated T-cell lymphoma-a clinicopathologic and array comparative genomic hybridization study. Hum Pathol 41: 1231-1237

7. Chan JK, Chan AC, Cheuk W, Wan SK, Lee WK, Lui YH et al (2011) Type II enteropathy-associated T-cell lymphoma: a distinct aggressive lymphoma with frequent $\gamma \delta$ T-cell receptor expression. Am J Surg Pathol 35:1557-1569

8. Sun J, Lu Z, Yang D, Chen J (2011) Primary intestinal T-cell and NKcell lymphomas: a clinicopathological and molecular study from China focused on type II enteropathy-associated T-cell lymphoma and primary intestinal NK-cell lymphoma. Mod Pathol 24:983-992

9. Chuang SS, Chang ST, Chuang WY, Huang WT, Hsieh PP, Tsou MH et al (2009) NK-cell lineage predicts poor survival in primary intestinal NK-cell and T-cell lymphomas. Am J Surg Pathol $33: 1230-1240$

10. Tse E, Gill H, Loong F, Kim SJ, Ng SB, Tang T et al (2012) Type II enteropathy-associated T-cell lymphoma: a multicenter analysis from the Asia Lymphoma Study Group. Am J Hematol 87:663-668

11. Katoh A, Ohshima K, Kanda M, Haraoka S, Sugihara M, Suzumiya J et al (2000) Gastrointestinal T cell lymphoma: predominant cytotoxic phenotypes, including alpha/beta, gamma/delta $\mathrm{T}$ cell and natural killer cells. Leuk Lymphoma 39:97-111

12. Tung CL, Hsieh PP, Chang JH, Chen RS, Chen YJ, Wang JS (2008) Intestinal T-cell and natural killer-cell lymphomas in Taiwan with special emphasis on 2 distinct cellular types: natural killer-like cytotoxic T cell and true natural killer cell. Hum Pathol 39:1018-1025

13. Tan SY, Chuang SS, Tang T, Tan L, Ko YH, Chuah KL et al (2013) Type II EATL (epitheliotropic intestinal T-cell lymphoma): a neoplasm of intra-epithelial T-cells with predominant $\mathrm{CD} 8 \alpha \alpha$ phenotype. Leukemia 27:1688-1696

14. Akiyama T, Okino T, Konishi H, Wani Y, Notohara K, Tsukayama C et al (2008) CD8+, CD56+ (natural killer-like) T-cell lymphoma involving the small intestine with no evidence of enteropathy: clinicopathology and molecular study of five Japanese patients. Pathol Int 58:626-634

15. Takeshita M, Nakamura S, Kikuma K, Nakayama Y, Nimura S, Yao $\mathrm{T}$ et al (2011) Pathological and immunohistological findings and genetic aberrations of intestinal enteropathy-associated $\mathrm{T}$ cell lymphoma in Japan. Histopathology 58:395-407

16. Kikuma K, Yamada K, Nakamura S, Ogami A, Nimura S, Hirahashi $M$ et al (2014) Detailed clinicopathological characteristics and possible lymphomagenesis of type II intestinal enteropathy-associated T-cell lymphoma in Japan. Hum Pathol 45:1276-1284

17. do Kim H, Lee D, Kim JW, Huh J, Park SH, Ha HK et al (2014) Endoscopic and clinical analysis of primary T-cell lymphoma of the gastrointestinal tract according to pathological subtype. J Gastroenterol Hepatol 29:934-943

18. Delabie J, Holte H, Vose JM, Ullrich F, Jaffe ES, Savage KJ et al (2011) Enteropathy-associated T-cell lymphoma: clinical and histological findings from the international peripheral T-cell lymphoma project. Blood 118(1):148-155

19. Morgan EA, Pihan GA, Said JW, Yu H, Pinkus JL, Dorfman DM et al (2014) Profile of CD103 expression in T-cell neoplasms: immunoreactivity is not restricted to enteropathy-associated T-cell lymphoma. Am J Surg Pathol 38:1557-1570

20. Kim JB, Kim SH, Cho YK, Ahn SB, Jo YJ, Park YS et al (2013) A case of colon perforation due to enteropathy-associated T-cell lymphoma. World J Gastroenterol 19:1841-1844

21. Kim YH, Lee JH, Yang SK, Kim TI, Kim JS, Kim HJ et al (2005) Primary colon lymphoma in Korea: a KASID (Korean Association for the Study of Intestinal Diseases) Study. Dig Dis Sci 50: 2243-2247 